\title{
Influência de Processos Redox na Resposta Inflamatória da Artrite Reumatóide
}

\section{Redox Influence on the Inflammatory Response in Rheumatoid Arthritis}

\author{
Lidiane Isabel Filippin $^{(1)}$, Rafael Vercelino ${ }^{(2)}$, Norma Possa Marroni( ${ }^{(3)}$, Ricardo Machado Xavier ${ }^{(4)}$
}

\section{RESUMO}

As espécies reativas de oxigênio (ROS) são produzidas, essencialmente, durante a fosforilação oxidativa e por ativação de células fagocíticas durante uma explosão oxidativa. A produção excessiva de ROS pode levar ao dano em lipídeos, proteínas, membranas e ácidos nucléicos e também serve como um importante sinalizador intracelular que amplifica respostas inflamatórias. Inúmeros estudos demonstram o envolvimento de ROS na patogênese das artropatias crônicas inflamatórias, como a artrite reumatóide. Acredita-se que as ROS possam atuar como segundos mensageiros para ativação do fator de transcrição nuclear kappa-B que orquestra a expressão de vários genes que perpetuam a resposta inflamatória. Portanto, o conhecimento da complexa interação entre essas vias poderia ser útil para desenvolver novas estratégias terapêuticas para a artrite reumatóide.

Palavras-chave: inflamação, estresse oxidativo, artrite reumatóide.

\section{INTRODUÇÃO}

Espécies reativas de oxigênio (ROS) são produzidas nas células por diversos estímulos fisiológicos e ambientais, tais como infecções, radiações UV e poluentes, os quais são coletivamente chamados de oxidantes. Curiosamente, as ROS também são consideradas como fatores de risco e aceleradores de doenças auto-imunes ${ }^{(1)}$, visto que existe uma estreita relação entre o estresse oxidativo e essas doenças ${ }^{(2)}$.

A artrite reumatóide (AR) é uma doença sistêmica inflamatória de etiologia auto-imune e caracterizada basicamente por sinovite crônica, simétrica e erosiva, preferencial-

\begin{abstract}
Reactive oxygen species (ROS) are produced mainly during the oxidative phosphorylation and by activated phagocytic cells during oxidative burst. The excessive production of ROS can damage lipids, protein, membrane and nucleic acids. They also serve as important intracellular signaling that amplify the inflammatory response. A lot of studies have demonstrated an role of ROS in the pathogenesis of inflammatory chronic artropathy, such as rheumatoid arthritis. It is known that an ROS can function as a second messenger to stimulate nuclear factor kappa- $B$ that orchestrate the expression of a spectrum of genes that perpetuate an inflammatory response. Therefore, an understanding of the complex interactions between these pathways might be useful for the development of novel therapeutics strategies for rheumatoid artritis.
\end{abstract}

Keywords: inflammation, oxidative stress, rheumatoid arthritis.

mente de articulações periféricas. A maioria dos pacientes apresenta o auto-anticorpo fator reumatóide reagente ${ }^{(3,4)}$. A AR tem prevalência de aproximadamente $0,46 \%$ na população brasileira ${ }^{(5)}$ e $1 \%$ na população mundial ${ }^{(6)}$.

$\mathrm{Na}$ tentativa de esclarecer a etiologia da AR, pesquisas sugerem fatores genéticos, defeitos na imunorregulação e mecanismos levando ao dano tecidual, incluindo o estresse oxidativo $^{(7)}$.

A definição clássica de estresse oxidativo é "um desequilíbrio entre pró-oxidantes e antioxidantes em favor do próoxidante" ${ }^{\prime(8)}$. No entanto, esse conceito vem se adaptando às recentes descobertas as quais demonstram que as ROS

Recebido em 28/9/2007. Aprovado, após revisão, em 02/12/2007. Declaramos que os autores Lidiane Isabel Filippin, Rafael Vercelino e Norma Possa Marroni não apresentam conflitos de interesse. O autor Ricardo Machado Xavier declara honorários de consultoria dos laboratórios Wyeth e Schering-Plough e verba de pesquisa dos laboratórios Abbott e Roché.

Serviços de Reumatologia e Serviço de Patologia Clínica do Hospital de Clínicas de Porto Alegre (HCPA), Faculdade de Medicina, Universidade Federal do Rio Grande do Sul (UFRGS)

Agência Financiadora: Coordenação de Aperfeiçoamento de Pessoal de Ensino Superior (Capes), Fundo de Incentivo a Pesquisa e Eventos (Fipe).

1. Fisioterapeuta, doutoranda do Programa de Pós-Graduação em Ciências Médicas da Faculdade de Medicina da UFRGS

2. Fisioterapeuta, doutorando em Fisiologia Humana pela UFRGS.

3. Professora titular, Ph.D. em Fisiologia, coordenadora do Laboratório de Hepatologia Experimental e Fisiologia do Hospital de Clínicas de Porto Alegre (HCPA

UFRGS), professora do Programa de Pós-Graduação em Toxicologia e Biologia Molecular da Universidade Luterana do Brasil.

4. Professor adjunto, Ph.D. em Imunologia, médico reumatologista do Serviço de Reumatologia do HCPA/UFRGS, coordenador do Laboratório de Biologia Molecular e Doenças Auto-Imunes e Infecciosas do HCPA.

Endereço para correspondência: Ricardo Machado Xavier, Serviço de Reumatologia do Hospital de Clínicas de Porto Alegre, Rua Ramiro Barcelos, 2.350, sl. 645,

CEP 90035-003, Porto Alegre, RS, e-mail: rmaxavier@hcpa.ufrgs.br 
podem atuar como segundos mensageiros de vias específicas na sinalização celular ${ }^{(9-11)}$. Esses dois conceitos têm sido recentemente incorporados dentro de uma nova definição: "um desequilíbrio entre oxidantes e antioxidantes em favor dos oxidantes, levando a um desarranjo da sinalização e do controle redox e/ou a um dano molecular ${ }^{(9)}$.

O objetivo desta revisão é relatar a participação das espécies ativas de oxigênio da sinalização redox na fisiopatologia da artrite reumatóide.

\section{FISIOPATOLOGIA DA AR}

A patologia da sinovite reumatóide caracteriza-se fundamentalmente por proliferação da membrana sinovial e erosão subseqüente da cartilagem articular e do osso subcondral. Embora se desconheça o evento desencadeador, parece envolver alguma estimulação antigênica específica de linfócitos T suscetíveis que expressam as moléculas de MHC apropriadas. Isto resulta em proliferação das células $\mathrm{T}$ e $\mathrm{B}$, estimulação da proliferação de vasos sangüíneos na membrana sinovial, acúmulo de células inflamatórias, incluindo leucócitos polimorfonucleares, proliferação de células sinoviais e desenvolvimento de um pannus invasivo de rápido crescimento. Este último cresce de modo quase semelhante a um tumor benigno, invade a cartilagem, ativa os condrócitos e libera enzimas proteolíticas que degradam a cartilagem e o osso, resultando, por fim, em erosões e destruição $\operatorname{articular}^{(12)}$.

$\mathrm{Na}$ sinovite, as células inflamatórias respondem com incremento na produção de prostaglandinas, citocinas e intensa formação de espécies reativas de oxigênio e radicais livres (RLs). Isso leva ao estresse oxidativo, que rapidamente amplifica o processo inflamatório, causando destruição articular, edema e dor ${ }^{(13,14)}$. Estudos demonstram que embora a característica persistente seja a inflamação, a geração de altos níveis de radicais livres na articulação inflamada e os níveis deficitários dos sistemas antioxidantes estão envolvidos na $\mathrm{AR}^{(15)}$.

\section{GERAÇÃO DAS ESPÉCIES REATIVAS DE OXIGÊNIO}

As espécies reativas de oxigênio, tais como ânion superóxido $\left(\mathrm{O}_{2}^{-}\right)$, peróxido de hidrogênio $\left(\mathrm{H}_{2} \mathrm{O}_{2}\right)$, ânion radical hidroxil $\left(\mathrm{HO}^{\bullet}\right)$ e outros, podem ter origem endógena e exógena. As principais fontes endógenas de geração de ROS são peroxissomos, NADPH oxidase, xantina oxidase, mitocôndria e citocromo P-450. Como vias exógenas, podem ser citadas radiação- $\gamma$, cigarro e solventes orgânicos ${ }^{(16,17)}$.
A excessiva formação endógena de radicais livres pode ser causada por: (1) ativação aumentada de fagócitos; (2) interrupção dos processos normais de transferência de elétrons na cadeia respiratória mitocondrial; (3) aumento da concentração de íons metálicos de transição por escape do grupamento heme de proteínas em locais de lesão ou doenças metabólicas; e (4) por níveis diminuídos das defesas antioxidantes. Entretanto, torna-se difícil determinar se na doença humana os radicais livres são a causa ou potencializam o dano patológico ${ }^{(18-20)}$.

Por outro lado, as espécies reativas de oxigênio são reconhecidas como importantes sinalizadoras intracelulares e estão envolvidas na regulação redox no interior das células do sistema imune ${ }^{(20-22)}$. Sabe-se que células fagocitárias, como macrófagos e neutrófilos, são ativadas sob condições oxidativas. Essa ativação é mediada pelo sistema da NADPH oxidase que resulta um marcado incremento no consumo de oxigênio e conseqüente produção de ânion superóxido ${ }^{(16)}$. A ativação da NADPH oxidase pode ser induzida por lipopolissacarídeos (LPS), lipoproteínas e citocinas, como inteferon-gama (IFN- $\gamma$ ), interleucina- 1 beta (IL- $1 \beta$ ) e fator de necrose tumoral alfa (TNF- $\alpha)^{(19,23)}$ (Figura 1$)$.

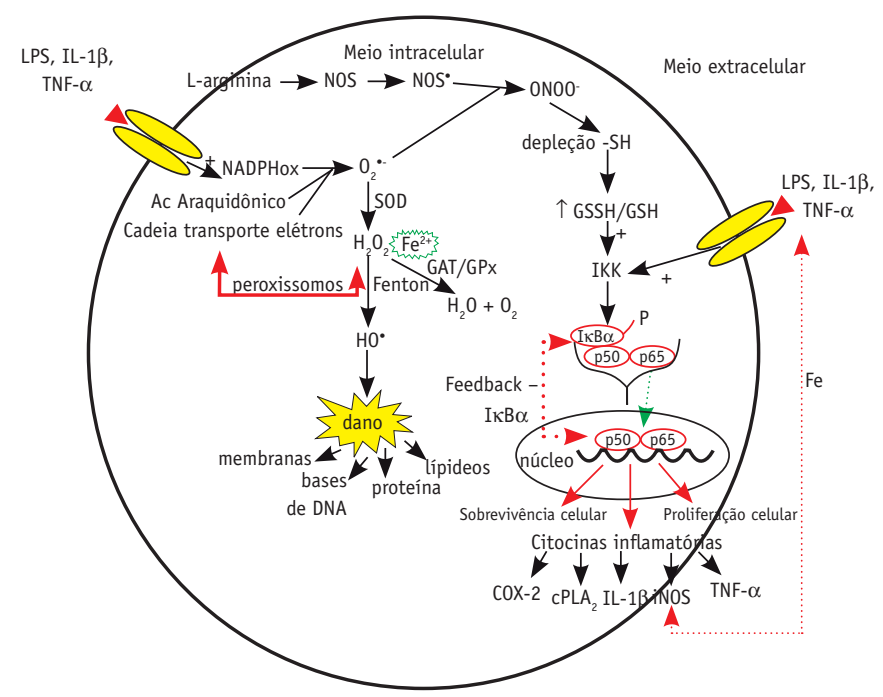

$\mathrm{O}_{2}{ }^{--}$= radical ânion superóxido; $\mathrm{H}_{2} \mathrm{O}_{2}=$ peróxido de hidrogênio; $\mathrm{HO}^{\bullet}$ = radical hidroxila; $\mathrm{SOD}$ = enzima endógena superóxido dismutase; $\mathrm{CAT}$ = enzima endógena catalase; $\mathrm{GPx}=$ enzima endógena glutationa; $\mathrm{L}=$ arginina - enzima precursora do óxido nítrico; $\mathrm{NO}=$ óxido nítrico; $\mathrm{NOS}=$ óxido nítrico sintase; $0 \mathrm{NOO}^{-}=$peroxinitrito; $-\mathrm{SH}=$ grupamento sulfidrila; GSSH/GHS = relação glutationa oxidada/ reduzida; $\mathrm{IKK}=$ inibidor kappa quinase; $\mathrm{I} \kappa \mathrm{B} \alpha=$ inibidor kappa $\mathrm{B} ; \mathrm{P}=$ fosforilação; ${ }_{c} P L A_{2}=$ fosfolipase $A_{2}$ citosólica; $\mathrm{COX}_{2}=$ ciclooxigenase $2 ; \mathrm{iNOS}=$ óxido nítrico sintase induzivel; $\mathrm{LPS}=$ lipopolissacarídeos; TNF- $\alpha=$ fator de necrose tumoral alfa; IL-1 $\beta$ = interleucina 1 beta.

Figura 1 - Formação das espécies ativas de oxigênio e nitrogênio (canto superior esquerdo), alvos dessas espécies reativas (canto inferior esquerdo), relação das ROS com a ativação do NF-KB e transcrição de citocinas pró-inflamatórias (à direita). 
O ânion superóxido é convertido em peróxido de hidrogênio espontaneamente e pode ser catalisado pela enzima superóxido dismutase (SOD). Essa enzima possui duas isoformas denominadas cobre-zinco-SOD e manganês-SOD, uma constitutiva e outra induzível, respectivamente ${ }^{(16)}$.

Em presença de íons ferro $\left(\mathrm{Fe}^{2+}\right)$ ou outros metais de transição, o superóxido e o peróxido de hidrogênio são convertidos, via reação de Fenton, a radical hidroxil $\left(\mathrm{HO}^{\bullet}\right)$, que é provavelmente responsável pela toxicidade celular associada às $\operatorname{ROS}^{(22)}$. Quando formado o $\mathrm{HO}^{\circ}$, ele rapidamente reagirá com a molécula mais próxima, que pode ser com lipídeos, proteínas ou bases de DNA. Isso acontece porque a taxa constante de reação do radical hidroxil é bastante alta quando comparada às outras espécies reativas $\left(\mathrm{k}>10^{9} \mathrm{M}^{-1} \mathrm{~s}^{-1}\right)^{(22)}$.

$\mathrm{O}$ ânion superóxido pode reagir com óxido nítrico formando o peroxinitrito $\left(\mathrm{ONOO}^{-}\right)$, uma espécie reativa de nitrogênio. A adição de $\mathrm{ONOO}$ às células, aos tecidos e aos fluidos corporais leva à rápida protonação, podendo resultar: depleção de grupos-SH e outros antioxidantes, oxidação e nitração de lipídeos, quebra de DNA, nitração e desaminação de bases de DNA (especialmente a guanina) $)^{(19,22)}$. A nitração em resíduos de tirosina é amplamente usada como um biomarcador da geração de $\mathrm{ONOO}^{-}$in vivo. Neste sentido, tem sido considerada como um importante instrumento para estudo do estresse nitrosativo em doenças humanas, ainda que não seja um biomarcador específico para $\mathrm{ONOO}^{-(22)}$.

Dentre os radicais de oxigênio e nitrogênio, o ONOO é capaz de depletar os grupamentos - $\mathrm{SH}$ e com isso alterar o balanço redox da glutationa no sentido do estresse oxidativo. Esse desequilíbrio no estado redox da glutationa induz por regulação redox ${ }^{(23)} \mathrm{O}$ inibidor kappa quinase (IKK) a fosforilar o inibidor kappa-B (IкB), possibilitando a translocação do fator de transcrição nuclear kappa-B (NF- $\mathrm{KB})$ para dentro do núcleo, levando à transcrição de diversos mediadores inflamatórios (Figura 1).

Se por um lado altas concentrações de ROS estão envolvidas na ativação do NF- $\kappa \mathrm{B}$ com a manutenção do processo inflamatório ${ }^{(24)}$, atuando como agente causal de dano a macromoléculas, por outro, sugere-se que baixas concentrações de ROS participem na regulação de diferentes funções nas células eucarióticas, tais como proliferação, biossíntese de hormônios, quimiotaxia, explosão oxidativa, apoptose e outras ${ }^{(20)}$.

Atualmente, sabe-se que espécies reativas podem contribuir na ativação das caspases, tanto por via intra quanto extracelular, levando à apoptose ${ }^{(22)}$. Em modelos animais de
AR, a indução de apoptose em sinóvia reumatóide por anticorpo monoclonal anti-FAS ou transfecção gênica de FAS ligante (FasL) melhora a artrite por eliminar tanto as células sinoviócitas proliferativas quanto as infiltradas linfocitárias na sinóvia inflamada ${ }^{(25,26)}$. Esses achados sugerem fortemente que a apoptose mediada por receptores extracelulares Fas pode ser um fator importante na fisiopatologia da $\mathrm{AR}^{(25)}$, e o estresse oxidativo seria um mediador dessa ação.

\section{PAPEL FISIOLÓGICO DAS ESPÉCIES REATIVAS DE OXIGÊNIO E DAS DEFESAS ANTIOXIDANTES}

As ROS participam em várias funções fisiológicas e são parte integrante na defesa contra microorganismos invasores. Elas são produzidas durante o metabolismo celular aeróbico normal e têm papel importante na manutenção do estado celular redox ${ }^{(2,20)}$.

O desequilíbrio no estado redox tem efeitos potencialmente deletérios sobre a biologia celular, anteriormente discutida. Por isso, existem vários mecanismos antioxidantes envolvidos na proteção de células e organismos para um eventual dano causado por quantidades excessivas desses mediadores altamente reativos ${ }^{(27,28)}$.

Os antioxidantes são importantes para manutenção de níveis baixos de radicais livres e espécies reativas não-radicais derivadas de radicais. Essas enzimas incluem superóxido dismutase, responsável pela dismutação do ânion superóxido. A SOD possui duas isoformas, uma constitutiva e outra induzível. Manganês-SOD (MnSOD) reside na mitocôndria e é induzível por citocinas através da via do NF- $\kappa \mathrm{B}$ e outros co-fatores $^{(22)}$, E cobre-zinco-SOD é constitutivo. Em eucariotos, localizam-se principalmente no citoplasma, mas também nos lisossomos, núcleo, espaços entre membrana interna e externa da mitocôndria e peroxissomos ${ }^{(22)}$.

A glutationa peroxidase (GPx) e catalase (CAT) é responsável pela dismutação do peróxido de hidrogênio ${ }^{(19)}$. A catalase reside na matriz do peroxissoma e, portanto, só é capaz de degradar o $\mathrm{H}_{2} \mathrm{O}_{2}$ produzido na matriz e não o $\mathrm{H}_{2} \mathrm{O}_{2}$ produzido no núcleo do peroxissoma. $\mathrm{O}$ peróxido de hidrogênio produzido no núcleo é transportado para o citoplasma por túbulos existentes no núcleo, onde a GTx fará a degradação ${ }^{(29)}$. A GPx degrada, além do peróxido de hidrogênio, outros peróxidos. É a primeira defesa mitocondrial do peróxido de hidrogênio e é regulada por p53 e por hipóxia ${ }^{(30)}$.

Participam ainda desse sistema antioxidante as enzimas não-enzimáticas provenientes da dieta, que incluem: vitamina $\mathrm{E}$, betacaroteno, vitamina $\mathrm{C}$ e a glutationa, esta última 
considerada o antioxidante não-enzimático hidrossolúvel mais importante por participar de inúmeras reações de oxirredução ${ }^{(20,27)}$. A glutationa atua como co-fator para GPx e outras enzimas, está envolvida em muitos outros processos metabólicos, incluindo o metabolismo do ascorbato, comunicação entre células, prevenção da oxidação de grupos tióis de proteínas e radioproteção. Sua principal contribuição é na manutenção do estado redox da célula ${ }^{(22)}$.

\section{AVALIAÇÃO DO ESTRESSE OXIDATIVO}

Atualmente, o uso de biomarcadores de estresse oxidativo pode fornecer uma relação entre o dano oxidativo, as macromoléculas (DNA, lipídeos e proteínas) e várias doenças. A grande quantidade de testes, tanto in vivo quanto ex vivo, inclui mensurações de oxidação de DNA, peroxidação lipídica e proteínas ${ }^{(24)}$.

Um dos produtos mais estudados quando falamos em danos no DNA é o produto final da oxidação da guanina por radicais hidroxil, o 8-hidroxi-desoxiguanosina (8-OHdG). Ele é um marcador de estresse oxidativo, isto é, sua presença no organismo indica oxidação das bases do DNA.

O teste cometa também é utilizado como marcador de dano oxidativo no DNA, é um método bastante sensível para mensurar quebras de células individuais e é amplamente utilizado para detecção de dano de DNA causado por câncer, radiações biológicas e toxicologia ambiental ${ }^{(24)}$.

A peroxidação lipídica pode ocorrer por via enzimática (ciclooxigenases e peroxidases) e por via não-enzimática (auto-oxidação) e, desta forma, pode ser avaliada por diferentes métodos dependendo da via de oxidação e do produto final mensurado. O malondialdeído é um produto secundário da peroxidação lipídica por via enzimática, derivado da $\beta$-ruptura de ácidos graxos poliinsaturados, tais como ácido linoléico, araquidônico e docosahexanóico. As substâncias reativas ao ácido tiobarbitúrico (TBA-RS) objetivam avaliar esse produto final. Um teste mais específico à formação do MDA é a cromatografia líquida (HPLC), na qual as partículas são separadas e somente o MDA é detectado ${ }^{(31)}$.

Um recente avanço na investigação do estresse oxidativo foi o uso das isoprostanas como marcador da peroxidação lipídica. As isoprostanas são substâncias produzidas in vivo, de maneira independente da enzima ciclooxigenase, pois se trata de isômeros produzidos por oxidação nãoenzimática do ácido araquidônico quando ainda esterificado na membrana ${ }^{(32)}$. Está estabelecido que a mensuração da isoprostana- $\mathrm{F}_{2}$ é a abordagem mais confiável para avaliar o estado oxidativo in vivo, fornecendo uma importante ferramenta para explorar o papel do estresse oxidativo em fatores de risco em diversas doenças, tais como as doenças cardiovasculares, doença de Alzheimer, esclerose múltipla, asma, hepatite, arteriosclerose, esclerodermia, osteoporose e doença de $\operatorname{Crohn}^{(33,34)}$.

Por fim, a oxidação de proteínas tem grande importância, pois com o dano oxidativo ocorrem fragmentação das cadeias e oxidação de quase todos os tipos de aminoácidos, com produção freqüente de compostos carbonilados, particularmente a partir de prolina, arginina e lisina. Essa modificação é facilmente mensurável ${ }^{(22)}$. O conteúdo carbonílico de proteínas é amplamente utilizado como marcador de dano oxidativo em proteínas, sob condições de estresse oxidativo. Há diversas técnicas para se medir a presença de grupo carbonila em proteínas. O método mais conveniente é o espectrofotométrico, com base na reação de DTNB com o grupo carbonila, que forma a hidrazona da proteína $^{(35)}$.

\section{EVIDÊNCIAS DO ESTRESSE OXIDATIVO NA AR}

$\mathrm{Na}$ artrite reumatóide, a perpetuação do processo inflamatório é atribuída às citocinas pró-inflamatórias, tais como o TNF- $\alpha$ e IL- $1 \beta$, conhecidos iniciadores da cascata de ativação do NF- $\kappa B^{(2)}$. Assim sendo, ao mesmo tempo em que o TNF- $\alpha$ participa positivamente na regulação do inibidor kappa quinase, permitindo que os dímeros do NF- $\kappa B$ (porções p50 e p65) migrem para o núcleo, ligando-se aos promotores de genes pró-inflamatórios ${ }^{(36)}$, estimula a ativação da NADPH oxidase (Figura 1).

A ativação do NF- $\kappa B$ participa não somente da resposta inflamatória, mas também da hiperproliferação sinovial na $\mathrm{AR}$, indicando que atua como um determinante para a patogênese da doença ${ }^{(25)}$.

Os radicais livres têm sido implicados como mediadores de dano tecidual na artrite reumatóide, em conjunto com as citocinas pró-inflamatórias. Experimentalmente, verifica-se que a excessiva produção de ROS pode levar a uma aceleração no dano à cartilagem articular e ativação de osteoclastos ${ }^{(37,38)}$.

Estudos com fluido sinovial e tecidos na AR têm demonstrado dano oxidativo do ácido hialurônico ${ }^{(39)}$, aparecimento de produtos da lipoperoxidação ${ }^{(40)}$, oxidação de lipoproteínas de baixa densidade (LDL) ${ }^{(41)}$ e incremento carbonil por oxidação protéica ${ }^{(42)}$. Evidências de dano 
oxidativo em cartilagem, colágeno extracelular e DNA também têm sido relatadas.

Além do dano à dupla camada lipídica causado pelos radicais livres, já bem estabelecido, tem-se investigado o dano de DNA, um importante alvo para a injúria oxidativa. Estudos avaliando o dano de DNA por intermédio do teste cometa em casos incidentes de artrite reumatóide demonstram elevados níveis de dano, o qual estava relacionado com o incremento do estresse oxidativo e decréscimo da capacidade antioxidante total ${ }^{(4)}$. Isso reitera as evidências de associação entre o estresse oxidativo e o dano articular de pacientes reumáticos.

Jikimoto et al. ${ }^{(43)}$ reportaram correlação entre atividade da doença e presença de estresse oxidativo em pacientes com artrite reumatóide. Outros estudos demonstraram correlações mais fracas ${ }^{(4)}$. Parece que a correlação mais forte se dá entre o dano de DNA e o índice de estresse oxidativo, ou seja, a relação entre os níveis de oxidações e da capacidade antioxidante $\{\mathrm{OSI}=[(\mathrm{TOS}, \mu \mathrm{mol} / \mathrm{L}) /$ (TAS, mmol trolox equivalent/L) x 100] $\}^{(4)}$.

Há relato demonstrado que as espécies ativas de nitrogênio têm papel importante na cronificação da reação inflamatória e destruição óssea e articular em pacientes com artrite reumatóide, osteoartrite e lúpus eritematoso sistêmico ${ }^{(44)}$. A formação de 3-nitrotirosina é um marcador relativamente específico de dano nitrosativo mediado pelo óxido nítrico. Khan e Siddiqui ${ }^{(44)}$ sugeriram que existe uma crescente evidência que o dano nitrosativo tem importante papel no estresse oxidativo da etiologia e patogênese do lúpus eritematoso sistêmico. Nesse estudo foram avaliados anticorpos presentes no líquido sinovial de 60 pacientes com diagnóstico de artrite reumatóide $(\mathrm{n}=30)$, osteoartrite $(\mathrm{n}=15)$ e lúpus eritematoso sistêmico $(\mathrm{n}=15)$. Foi sugerido que os radicais livres de nitrogênio podem produzir inflamação e que os níveis de 3-nitrotirosina também são correlacionados com a atividade da doença.

A síntese de proteínas do choque térmico (HSP), também conhecidas como proteínas de estresse, pode ser desencadeada por exposição das células a metais pesados, agentes oxidantes, etanol e infecções. Algumas dessas proteínas existem na forma constitutiva e outras aumentam drasticamente sob condições oxidativas ${ }^{(22,45)}$. As HSPs inibem a ativação do NF-kB pela inibição do IKK pelas prostaglandinas ciclopentenônicas (CP-PGs). Essas prostaglandinas são formadas pelo acúmulo destas nos meios intra e extracelulares (Figura 2).

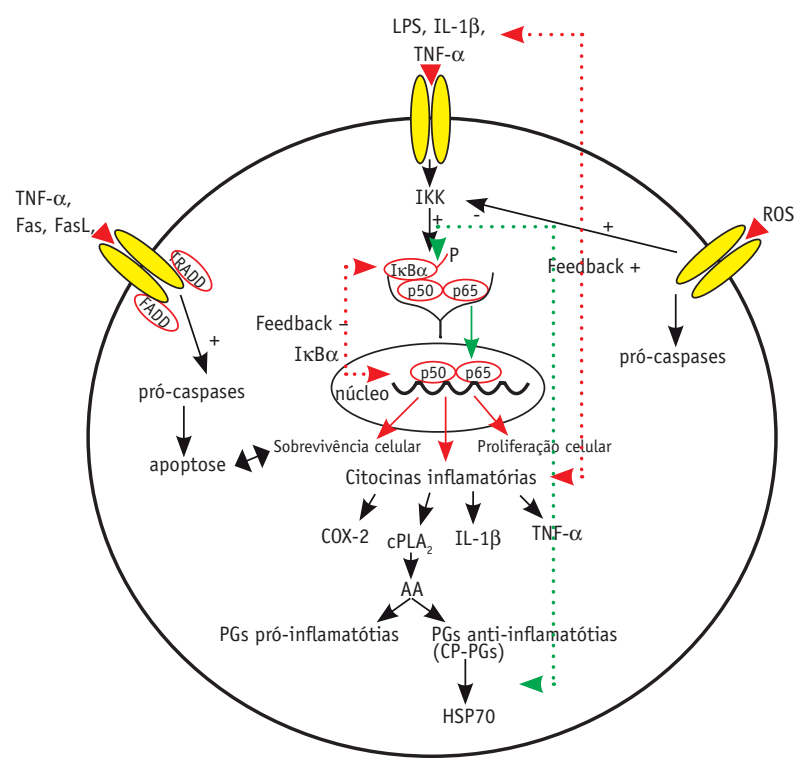

Figura 2 - Interação entre as ROS, citocinas inflamatórias e receptores de morte celular. As ROS, assim como as citocinas inflamatórias, ativam o IKK que dará início à cascata do NF- $\kappa B$, levando a célula a três possibilidades: sobrevivência celular, produção de citocinas inflamatórias e proliferação celular. Podem também ativar pró-caspases, assim como os receptores extracelulares de morte, levando a célula à apoptose. Interessantemente, a produção de citocinas inflamatórias pelo NF- $\mathrm{KB}$ libera CPLA ${ }_{2}$, que tem a função de hidrolisar o ácido araquidônico dos fosfolípides de membrana que, por sua vez, podem ser sintetizados por diferentes vias (COX, LOX e EPOX) em prostaglandinas. 0 acúmulo de PGs no meio intracelular leva à produção de prostaglandinas ciclopentenônicas que podem inibir a fosforilação do $\mathrm{I} \kappa \mathrm{B} \alpha$ bloqueando o processo. Da mesma maneira, atuam as HSPs.

\section{TRATAMENTO FARMACOLÓGICO DA AR E O ESTRESSE OXIDATIVO}

Atualmente a droga de primeira escolha para o tratamento da artrite reumatóide é o metotrexato, agente antagonista do folato desenvolvido inicialmente para o tratamento de neoplasias malignas. $\mathrm{Na} \mathrm{AR}$, as doses empregadas são muito inferiores às analgésicas, e não se acredita que sua eficácia no controle da doença esteja relacionada a essa ação antiproliferativa. Outros mecanismos têm sido propostos, incluindo a inibição da síntese dos compostos tóxicos espermina e espermidina e o acúmulo extracelular de adenosina, a qual tem conhecida ação antiinflamatória atuando por intermédio dos receptores de adenosina ${ }^{(46)}$. Já foi demonstrado também que o metotrexato é capaz de suprimir, direta ou indiretamente, a geração de metabólitos ativos de oxigênio induzida pela interleucina-6, produzida após estímulo com TNF- $\alpha$ nas células sinoviais da artrite reumatóide ${ }^{(47)}$, bem como em polimorfonucleares ${ }^{(48)}$. Contudo, estudos sugerem que baixas doses de metotrexato induzem apoptose com envolvimento de ROS mais acentuada em linhagem de células linfócitos $\mathrm{T}$ do que monócitos ${ }^{(49)}$. 
Mais recentemente, agentes biológicos (anticorpos monoclonais ou proteínas recombinantes) com ação antagonista do TNF- $\alpha$ demonstraram marcante eficácia no controle dos sinais flogísticos e na progressão radiológica da AR. Esses agentes não parecem atuar diretamente sobre a produção de radicais do oxigênio, mas levam à inibição da ativação e quimiotaxia dos neutrófilos para o tecido sinovial, com conseqüente redução da geração desses radicais ${ }^{(50)}$.

Estudos com inibidores de TNF- $\alpha$, etanercepte e infliximabe demonstraram redução de marcadores de estresse oxidativo em pacientes com artrite reumatóide. Nesse estudo foram avaliados 22 pacientes com AR e, além dos parâmetros de estresse oxidativo, foram avaliados parâmetros laboratoriais e clínicos. Os resultados demonstraram queda importante dos parâmetros oxidativos nos pacientes tratados com etanercepte por seis meses, as variáveis em estudo apresentaram boa correlação com os dados clínicos, porém fraca correlação com dados laboratoriais ${ }^{(51)}$.

Recentes estudos epidemiológicos têm demonstrado correlação inversa entre os níveis de exposição antioxidantes, analisados por um questionário padronizado incluindo dados demográficos, história reprodutiva e médica, uso de terapia hormonal, história de fumo e outros fatores de estilo de vida e incidência de artrite reumatóide. Essas observações levantam a hipótese de que alimentação balanceada e suplementação de antioxidantes poderiam proteger contra o desenvolvimento ou agravamento da doença, pois tem sido relatado que pacientes com artrite reumatóide possuem

\section{REFERÊNCIAS}

1. Avalos I, Chung CP, Oeser A, et al.: Oxidative stress in systemic lupus erythematosus: relationship to disease activity and symptoms. Lupus 16(3): 195-200, 2007.

2. Surh YJ: Oxidative Stress, Inflammation, and Health. Packer L (ed.). Londres: Taylor \& Francis, 2005.

3. Kinne RW, Bräuer R, Stuhlmüller B, et al.: Macrophages in rheumatoid arthritis. Arthritis Res 2(3): 189-202, 2000.

4. Altindag O, Karakoc M, Kocyigit A, et al.: Increased DNA damage and oxidative stress in patients with rheumatoid arthritis. Clin Biochem 40(3-4): 167-71, 2007.

5. Senna ER, De Barros AL, Silva EO, et al.: Prevalence of rheumatic diseases in Brazil: a study using the COPCORD approach. J Rheumatol 31(3): 594-7, 2004.

6. Lee DM, Weinblatt ME: Rheumatoid arthritis. Lancet 358(9285): 903-11, 2001 níveis mais baixos de antioxidantes, incluindo vitamina $\mathrm{C}$, vitamina $\mathrm{E}$, betacaroteno, selênio e zinco quando comparados com pacientes controles ${ }^{(49,52,53)}$.

Além das espécies ativas de oxigênio, as espécies ativas de nitrogênio também têm sido investigadas em doenças reumatológicas auto-imunes. Essa ligação dá-se pela participação das EAN na ativação do NF- $\kappa B$, visto que a formação de peroxinitrito interfere no balanço redox da glutationa. Esses estudos indicam que os doadores das EAN acarretam ativação e incremento do NF- $\kappa \mathrm{B}$, do sistema proteolítico bem como a degradação de proteínas específicas do músculo esquelético ${ }^{(54,55)}$.

\section{CONCLUSÃO}

As artropatias crônicas inflamatórias, como a artrite reumatóide, são caracterizadas por um complexo processo inflamatório progressivo e crônico, que envolve inúmeros fatores de transcrição e sinalizadores moleculares. Numerosos trabalhos têm observado que existe uma relação entre o dano oxidativo, causado a lipídeos, proteínas e DNA, e a manutenção do processo inflamatório dessa doença, bem como os efeitos inibidores das medicações com ação anti-reumática sobre os processos oxidativos. Entretanto, a natureza dessa relação ainda não foi bem determinada e requer mais estudos. Esse conhecimento tem um potencial importante para oferecer uma compreensão dos mecanismos de ação das terapias atuais e, principalmente, para o desenvolvimento de novas estratégias terapêuticas.

7. Ozkan Y, Yardým-Akaydýn S, Sepici A, Keskin E, Sepici V, Simsek B: Oxidative status in rheumatoid arthritis. Clin Rheumatol 26(1): 64-8, 2007.

8. Sies H: Oxidative Stress: Introdutory remaks. v.1. London: Academic Press, 1985. p. 1-8.

9. Jones DP: Disruption of mitochondrial redox circuitry in oxidative stress. Chem Biol Interact 163(1-2): 38-53, 2006.

10. Forman HJ, Fukuto JM, Torres M: Redox signaling: thiol chemistry defines which reactive oxygen and nitrogen species can act as second messengers. Am J Physiol Cell Physiol 287(2): C246-56, 2004.

11. Rosa RM, Roehrs R, Saffi J, Henriques JAP: “O papel da reparação de lesões oxidativas induzidas no DNA na redução do risco de desenvolvimento de câncer”. In: Salvador M, Henriques JAP. (Orgs.). Radicais livres e a resposta celular ao estresse oxidativo. 1.ed. Canoas: Editora da Ulbra, 2004. 
12. Andreoli TE, Carpenter CCJ, Benett JC, Plum F: Medicina Interna Básica. 4.ed. Rio de Janeiro: Guanabara Koogan, 1997. p. $568-70$.

13. Vignaud A, Cebrian J, Martelly I, Caruelle JP, Ferry A: Effect of anti-inflammatory and antioxidant drugs on the long-term repair of severely injured mouse skeletal muscle. Exp Physiol 90(4): 487-95, 2005.

14. Henrotin Y, Kurz B, Aigner T: Oxygen and reactive oxygen species in cartilage degradation: friends or foes? Osteoarthritis Cartilage 13(8): 643-54, 2005.

15. Fang YZ, Yang S, Wu G: Free radicals, antioxidants, and nutrition. Nutrition 18(10): 872-9, 2002.

16. Hitchon CA, HS El-Gabalawy: Oxidation in rheumatoid arthritis. Arthritis Res Ther 6(6): 265-78, 2004.

17. Belló-Klein A, Llesuy SF: Estresse Oxidativo e Antioxidantes. Canoas: Ulbra, 2002. p. 15-19; 21-32.

18. Halliwel B, Gutteridge JCM: Free Radicals in Biology and Medicine. 3.ed. Londres: Oxford University Press, 1999.

19. Droge W: Free radicals in the physiological control of cell function. Physiol Rev 82(1): 47-95, 2002.

20. Oktyabrsky ON, Smirnova GV: Redox regulation of cellular functions. Biochemistry (Mosc) 72(2): 132-45, 2007.

21. Griffiths HR: ROS as signalling molecules in T cells - evidence for abnormal redox signalling in the autoimmune disease, rheumatoid arthritis. Redox Rep 10(6): 273-80, 2005.

22. Barry Halliwell JG: Free Radicals in Biology and Medicine. 4.ed. New York: Oxford University Press, 2007.

23. Bitencoutt PIH: Metabolismo do Ácido Araquidômico na Sepse, in Sepse. Manole, São Paulo, 2007.

24. Hwang ES, Kim GH: Biomarkers for oxidative stress status of DNA, lipids, and proteins in vitro and in vivo cancer research. Toxicology 229(1-2): 1-10, 2007.

25. Okamoto T, Sakurada S, Yang JP, Merin JP: Regulation of NFkappa B and disease control: identification of a novel serine kinase and thioredoxin as effectors for signal transduction pathway for NF-kappa B activation. Curr Top Cell Regul 35: 149-61, 1997.

26. Kim WU, Yoo SA, Min SY, et al.: Hydroxychloroquine potentiates Fas-mediated apoptosis of rheumatoid synoviocytes. Clin Exp Immunol 144(3): 503-11, 2006.

27. Blair IA: Endogenous glutathione adducts. Curr Drug Metab 7(8): 853-72, 2006.

28. Soneja A, Drews M, Malinski T: Role of nitric oxide, nitroxidative and oxidative stress in wound healing. Pharmacol Rep 57 Suppl: 108-19, 2005.

29. Fritz R, Bol J, Hebling U, et al.: Compartment-dependent management of $\mathrm{H}(2) \mathrm{O}(2)$ by peroxisomes. Free Radic Biol Med 42(7): 1119-29, 2007.

30. Bierl C, Voetsch B, Jin RC, Handy DE, Loscalzo J: Determinants of human plasma glutathione peroxidase (GPx-3) expression. J Biol Chem. 279(26): 26839-45, 2004.

31. Del Rio D, Stewart AJ, Pellegrini N: A review of recent studies on malondialdehyde as toxic molecule and biological marker of oxidative stress. Nutr Metab Cardiovasc Dis 15(4): 316-28, 2005.
32. Montuschi P, Barnes PJ, Roberts 2nd LJ: Isoprostanes: markers and mediators of oxidative stress. Faseb J 18(15): 1791-800, 2004.

33. Montuschi P, Barnes P, Roberts 2nd LJ: Insights into oxidative stress: the isoprostanes. Curr Med Chem 14(6): 703-17, 2007.

34. Cracowski JL, Marpeau C, Carpentier PH, et al.: Enhanced in vivo lipid peroxidation in scleroderma spectrum disorders. Arthritis Rheum 44(5): 1143-8, 2001.

35. Lushchak V, Semchyshyn H, Mandryk S, Lushchak O: Possible role of superoxide dismutases in the yeast Saccharomyces cerevisiae under respiratory conditions. Arch Biochem Biophys 441(1): 35-40, 2005.

36. Moynagh PN: The NF-kappaB pathway. J Cell Sci 118(Pt 20): 4589-92, 2005.

37. Goldring SR: Pathogenesis of bone erosions in rheumatoid arthritis. Curr Opin Rheumatol 14(4): 406-10, 2002.

38. Miossec P: An update on the cytokine network in rheumatoid arthritis. Curr Opin Rheumatol 16(3): 218-22, 2004.

39. Grootveld M, Henderson EB, Farrell A, Blake DR, Parkes HG, Haycock P: Oxidative damage to hyaluronate and glucose in synovial fluid during exercise of the inflamed rheumatoid joint. Detection of abnormal low-molecular-mass metabolites by protonn.m.r. spectroscopy. Biochem J 273(Pt 2): 459-67, 1991.

40. Taysi S, Polat F, Gul M, Sari RA, Bakon E: Lipid peroxidation, some extracellular antioxidants, and antioxidant enzymes in serum of patients with rheumatoid arthritis. Rheumatol Int 21(5): 200-4, 2002.

41. Dai L, Polat F, Gul M, Sari RA, Bakan E: Evidence for oxidised low density lipoprotein in synovial fluid from rheumatoid arthritis patients. Free Radic Res 32(6): 479-86, 2000.

42. Dalle-Donne I, Rossi R, Giustarini D, Milzani A, Colombo R: Protein carbonyl groups as biomarkers of oxidative stress. Clin Chim Acta 329(1-2): 23-38, 2003.

43. Jikimoto T, Nishikubo Y, Koshiba M, et al.: Thioredoxin as a biomarker for oxidative stress in patients with rheumatoid arthritis. Mol Immunol 38(10): 765-72, 2002.

44. Khan F, Siddiqui AA: Prevalence of anti-3-nitrotyrosine antibodies in the joint synovial fluid of patients with rheumatoid arthritis, osteoarthritis and systemic lupus erythematosus. Clin Chim Acta 370(1-2): 100-7, 2006.

45. Zugel U, Kaufmann SH: Role of heat shock proteins in protection from and pathogenesis of infectious diseases. Clin Microbiol Rev 12(1): 19-39, 1999.

46. Cronstein BN: Low-dose methotrexate: a mainstay in the treatment of rheumatoid arthritis. Pharmacol Rev 57(2): 163-72, 2005.

47. Sung JY, Hong JH, Kang HS, et al.: Methotrexate suppresses the interleukin- 6 induced generation of reactive oxygen species in the synoviocytes of rheumatoid arthritis. Immunopharmacology. 47(1): 35-44, 2000.

48. Laurindo IM, Mello SB, Cossermelli W: Influence of low doses of methotrexate on superoxide anion production by polymorphonuclear leukocytes from patients with rheumatoid arthritis. J Rheumatol 22(4): 633-8, 1995. 
49. Mangge HJ, Hermann J, Schauenstein K: Diet and rheumatoid arthritis - a review. Scand J Rheumatol 28(4): 201-9, 1999.

50. den Broeder AA, Wanten GJ, Oyen WJ, Naber T, van Riel PL, Barrera P: Neutrophil migration and production of reactive oxygen species during treatment with a fully human anti-tumor necrosis factor-alpha monoclonal antibody in patients with rheumatoid arthritis. J Rheumatol 30(2): 232-7, 2003.

51. Kageyama Y, Takahashi M, Nagafusa T, Torikai E, Nagano A: Etanercept reduces the oxidative stress marker levels in patients with rheumatoid arthritis. Rheumatol Int, 28(3): 245-51, 2008.

52. Cerhan JR, Saag KG, Merlino LA, Mikuls TR, Criswell LA: Antioxidant micronutrients and risk of rheumatoid arthritis in a cohort of older women. Am J Epidemiol 157(4): 345-54, 2003.

53. Hagfors L, Leanderson P, Sköldstam L, Anderson J, Johansson $\mathrm{G}$ : Antioxidant intake, plasma antioxidants and oxidative stress in a randomized, controlled, parallel, Mediterranean dietary intervention study on patients with rheumatoid arthritis. Nutr J 2: 5, 2003.

54. Bar-Shai M, Reznick AZ: Peroxynitrite induces an alternative NF-kappaB activation pathway in L8 rat myoblasts. Antioxid Redox Signal 8(3-4): 639-52, 2006.

55. Bar-Shai M, Reznick AZ: Reactive nitrogen species induce nuclear factor-kappaB-mediated protein degradation in skeletal muscle cells. Free Radic Biol Med 40(12): 2112-25, 2006. 